\title{
Significance of TNF- $\alpha$ and IL-6 expression in invasive pituitary adenomas
}

\author{
J.L. Wu ${ }^{1}$, J.Y. Qiao ${ }^{2}$ and Q.H. Duan ${ }^{1}$
}

'Department of Pathology, Chengde City Center Hospital, Shuangqiao District, Guangren, Chengde, Hebei, China

${ }^{2}$ Department of Neurosurgery, Chengde City Center Hospital, Shuangqiao District, Guangren, Chengde, Hebei, China

Corresponding author: J.Y. Qiao

E-mail: qjianyong_a@163.com

Genet. Mol. Res. 15 (1): gmr.15017502

Received August 24, 2015

Accepted January 12, 2016

Published March 18, 2016

DOI http://dx.doi.org/10.4238/gmr.15017502

\begin{abstract}
The aim of this study was to investigate expression of tumor necrosis factor- $\alpha$ (TNF- $\alpha$ ) and interleukin-6 (IL-6) in invasive pituitary adenomas (IPAs). The streptavidin peroxidase immunohistochemical method was employed to detect their expression in 40 cases of IPA and 40 of non-invasive pituitary adenoma (NIPA). TNF- $\alpha$ and IL- 6 were found to be upregulated in IPA tissue compared with that of NIPA $(P<0.05)$. These proteins may therefore play important roles in the occurrence and progression of IPA.
\end{abstract}

Key words: Invasive pituitary adenomas; TNF-a; IL-6; Immunohistochemistry 


\section{INTRODUCTION}

Pituitary adenomas are common intracranial tumors that derive from anterior pituitary cells. Being observed at rates between 1 in 10,000 and 7 in 100,000, pituitary adenomas rank third only to meningioma as and cerebral gliomas in terms of prevalence, and account for $10 \%$ of all intracranial tumors (Wang, 2005). Most pituitary adenomas resemble benign tumors, presenting with restricted growth and low incidence of distant metastasis. Total surgical resection can result in good prognosis. However, some pituitary adenomas show invasive growth to regions around the saddle area, penetrating the capsule and exceeding the pituitary fossa. These tumors occasionally reach the sphenoid sinus, cavernous sinus, anterior skull base, and hypothalamus, causing damage to structures around the saddle area. Such tumors are difficult to completely resect by surgery, and postoperative recurrence is usually high (Roelfsema et al., 2012). This represents a major difficulty in neurosurgery. Although invasive pituitary adenomas (IPAs) are considered benign tumors histologically, they can demonstrate malignant behavior (Rey et al., 1986). Therefore, pituitary adenomas are divided into IPAs, non-invasive pituitary adenomas (NIPAs), and other types. The concept of IPA was first proposed by Jefferson (1940) in 1940 and later received wide recognition, as it provided an explanation for incomplete resection and high recurrence. Studying the pathogenesis of IPA and exploring new therapies are of great importance in improving prognosis. Many studies have been carried out into the roles of tumor necrosis factor- $\alpha$ (TNF- $\alpha$ ) and interleukin-6 (IL-6), but few have focused on their relationship with IPA. Here, we study their expression in IPA tissue and discuss its clinical significance, so as to shed new light on the treatment and prognostic assessment of IPA.

\section{MATERIAL AND METHODS}

\section{Specimens}

Specimens were surgically resected between October 2012 and June 2014 at Chengde Central Hospital and Affiliated Hospital of Chengde Medical College from patients pathologically confirmed as having pituitary adenomas. The adenoma as from which these specimens derived were categorized as grade 3-4 according to the Wilson-Hardy classification. When preoperative magnetic resonance imaging and intraoperative findings indicated that tumors had invaded structures near the saddle area (e.g., the cavernous sinus and bone of the sellar floor), they were considered to be IPAs. Based on these criteria, 40 cases of IPA and 40 of NIPA were included in this study. All specimens were fixed in $4 \%$ formaldehyde.

\section{Reagents and equipment}

\section{Main reagents}

The following reagents were used in our protocols: mouse anti-human TNF- $\alpha$ monoclonal immunoglobulin G ( $\lg G$ ) antibody, mouse anti-human IL-6 monoclonal IgG antibody (Santa Cruz Biotechnology, Dallas, TX, USA); Instant Immunohistochemistry Kit, 3,3'-diaminobenzidine (DAB) color reagent, goat serum (Beijing Zhongshan Golden Bridge Biotechnology Co., Ltd., Beijing, China); dimethylbenzene, alcohol, $3 \%$ hydrogen peroxide, methanol, phosphate-buffered saline (PBS), citrate buffer, hematoxylin, ammonia, neutral balsam. 


\section{Equipment}

The following equipment was used in our protocols: CSR-1-30 ultrapure water system (Beijing Aisitaike Technology Development Co., Ltd., Beijing, China); microwave oven, pressure cooker (Joyoung, Jinan, China); $37^{\circ} \mathrm{C}$ thermostatic incubator (Shanghai Jinghong Experimental Facilities Co., Ltd., Shanghai, China); $4^{\circ} \mathrm{C}$ refrigerator (Haier, Qingdao, China); micropipettor (Eppendorf, Hauppauge, NY, USA); automatic dehydration machine, biological tissue embedding machine (Leica, Wetzlar, Germany); BX43 microscope (Olympus, Tokyo, Japan); microscope imaging system (Motic, Xiamen, China).

\section{Methods}

\section{Hematoxylin and eosin (H\&E) staining, fixation, and section preparation}

Pituitary tumor specimens were fixed in $10 \%$ formalin for $24 \mathrm{~h}$, before being cut into appropriately sized blocks. Tissues were de hydrated using solutions of $80,85,90$, and $95 \%$ ethanol, and anhydrous ethanol I and II, being incubated for $1 \mathrm{~h}$ with each solution. Subsequently, the tissues were cleared with dimethylbenzene I and II for $2 \mathrm{~h}$ in each, and immersed in paraffin I, II, and III for $1.5 \mathrm{~h}$ in each. The dehydrated tissues were then placed into an embedding cassette and melted paraffin was added dropwise to fully immerse the tissue blocks. Once completely solidified during the embedding machine cooling stage, the paraffin-embedded tissues were cut into slices of $4 \mu \mathrm{m}$. Using a spreading machine, these were then attached to glass slides and baked in an oven at $80^{\circ} \mathrm{C}$ for $15 \mathrm{~min}$. The sections were then subjected to H\&E staining and covers lips were applied.

\section{Immunohistochemical method}

IPA and NIPA specimens were washed with distilled water to remove the formalin from their surfaces. Tissue blocks of the appropriate size were then dehydrated using an automatic dehydration machine and the following solutions (being incubated for $1 \mathrm{~h}$ in each): $80,85,90$, and $95 \%$ ethanol, and anhydrous ethanol I and II. This was followed by clearing using dimethylbenzene $\mathrm{I}$ and II for $2 \mathrm{~h}$ in each. Finally, the tissues were immersed in paraffin I, II, and III for $1.5 \mathrm{~h}$ in each, before being embedded.

\section{Slicing and baking}

All specimens were sliced into consecutive $4-\mu \mathrm{m}$ sections and attached to glass slides, which were baked in an oven at $60^{\circ} \mathrm{C}$ for $2 \mathrm{~h}$.

\section{Dewaxing, removal of dimethylbenzene, and washing with distilled water}

Tissues were incubated with dimethylbenzene twice for $15 \mathrm{~min}$, anhydrous ethanol twice for $10 \mathrm{~min}, 95,80$, and $70 \%$ ethanol for $10 \mathrm{~min}$ in each, then washed with double-distilled water twice for $5 \mathrm{~min}$, before being immersed in $0.01 \mathrm{M}$ PBS three times for $5 \mathrm{~min}$. Deactivation of endogenous peroxidases was achieved by incubation with a $3 \%$ hydrogen peroxide-methanol solution for $10 \mathrm{~min}$ at $37^{\circ} \mathrm{C}$, then $0.01 \mathrm{M}$ PBS three times for $5 \mathrm{~min}$, also at $37^{\circ} \mathrm{C}$. 


\section{Antigen retrieval}

Citrate buffer $(0.01 \mathrm{M}), \mathrm{pH} 6.0$, was placed into a pressure cooker and heated by induction until boiling. After switching off the power, the sections were placed into the buffer and heated until steam was emitted for $1.5 \mathrm{~min}$. The power was then switched off again and the sections were cooled for $15 \mathrm{~min}$, before being washed with $0.01 \mathrm{M}$ PBS three times for $5 \mathrm{~min}$.

\section{Addition of sealing serum}

The tissues were incubated with goat serum at $37^{\circ} \mathrm{C}$ for $15 \mathrm{~min}$ without washing.

\section{Incubation with primary antibody}

The slides were incubated with an excess of mouse anti-human monoclonal antibody solution (TNF- $\alpha$ or IL-6; 1:100 dilution) at $4^{\circ} \mathrm{C}$ overnight. This was followed by three 5-min $0.01-\mathrm{M}$ PBS washes.

\section{Incubation with secondary antibody}

Tissues were exposed to biotinylated anti-mouse secondary antibody at $37^{\circ} \mathrm{C}$ for $20 \mathrm{~min}$ in an incubator, and subsequently washed three times with $0.01 \mathrm{M}$ PBS for 5 min each.

\section{$D A B$ color development}

DAB color reagent was added at room temperature to initiate color development for 5-10 min. The reaction was terminated by washing with distilled water.

\section{Hematoxylin counterstaining, dehydration, and clearing}

Sections were immersed in hematoxylin for $90 \mathrm{~s}$ and washed under flowing water for 5 min. After differentiation with a hydrochloric acid-alcohol mixture for 20-30 s, they were again washed under flowing water for $15 \mathrm{~min}$. Dehydration by ethanol gradient was carried out $(70,80,90,95 \%$ I and II, then $100 \% \mathrm{I}$ and II), followed by clearing with dimethylbenzene. Finally, sections were sealed with neutral balsam. PBS was used as a negative immunohistochemical staining control, while the positive section provided by the reagent manufacturer was used as a positive control.

\section{Standards for judging immunohistochemical results}

TNF- $\alpha$ and IL- 6 were mainly expressed in the cytoplasm, and positive expression level was calculated according to the percentage of positive cells observed and immunohistochemical scores. Dense regions of tumor cells within the tissue sections were observed under a microscope (10 $\times 20$ magnification), and five fields of view were randomly selected. Positive-cell scoring criteria were as follows: 0 points for $<10 \%$ positive cells; 1 point for $10-25 \%$; 2 points for $26-50 \%$; 3 points for $>50 \%$. Immunohistochemical staining scores were as follows: 0 points for no color; 1 point for light yellow; 2 points for yellowish brown; 3 points for deep brown or tan. The sum of the two scores 
was calculated and the following qualitative categories were used: 0 points represented a negative sample (-), 1-2 points low expression (+), 3-4 points medium expression (++), and 5-6 points high expression (+++).

\section{Statistics}

The SPSS 19.0 software (IBM Corp., Armonk, NY, USA) was used for all statistical analysis, and the chi-square test was performed. $\mathrm{P}<0.05$ indicated statistical significance.

\section{RESULTS}

\section{H\&E staining of IPA and NIPA specimens}

IPA specimens showed multinucleation, with active mitosis and obvious cell nucleoli, and interstitial microvessel density was high. However, these characteristics were not as evident in NIPA specimens (Figure 1).

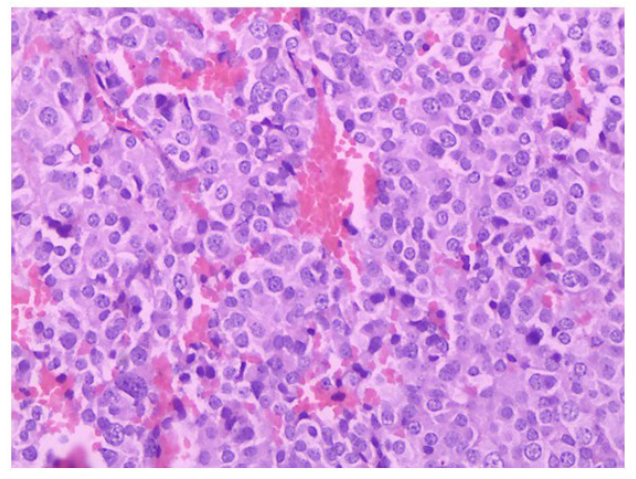

IPA

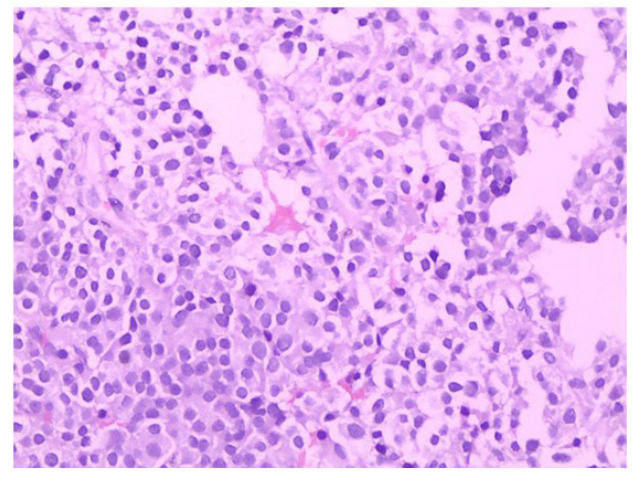

NIPA

Figure 1. Hematoxylin and eosin staining of invasive (IPA) and non-invasive (NIPA) pituitary adenoma specimens (10 x 20 magnification).

\section{Expression of TNF- $\alpha$ in IPA and NIPA specimens}

TNF- $\alpha$ staining was not observed in the negative control group. The proportion of IPA specimens demonstrating positive expression of TNF- $\alpha$ was $65 \%$, while among the NIPA samples, this figure was $25 \%(P<0.05$; Table 1 and Figure 2$)$.

Table 1. Expression of TNF- $\alpha$ in invasive (IPA) and non-invasive (NIPA) pituitary adenoma specimens.

\begin{tabular}{|c|c|c|c|c|c|c|c|}
\hline \multirow[t]{2}{*}{ Type of tumor } & \multirow[t]{2}{*}{$\mathrm{N}$} & \multicolumn{4}{|c|}{ TNF- $\alpha$ expression } & \multirow[t]{2}{*}{$\chi^{2}$ value } & \multirow[t]{2}{*}{$P$} \\
\hline & & - & + & ++ & +++ & & \\
\hline NIPA & 40 & 30 & 7 & 3 & 0 & 12.93 & $<0.05$ \\
\hline IPA & 40 & 14 & 8 & 12 & 6 & & \\
\hline
\end{tabular}




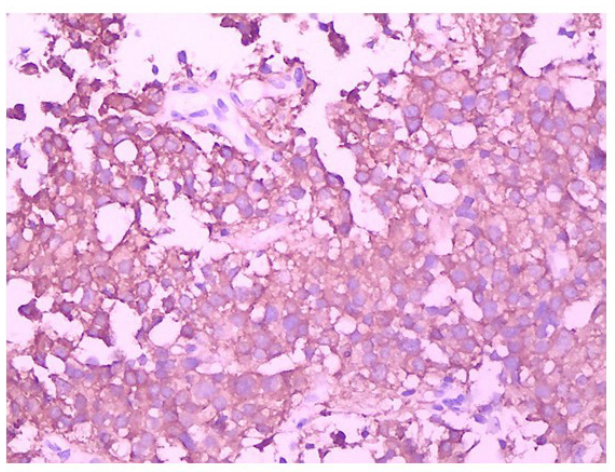

IPA

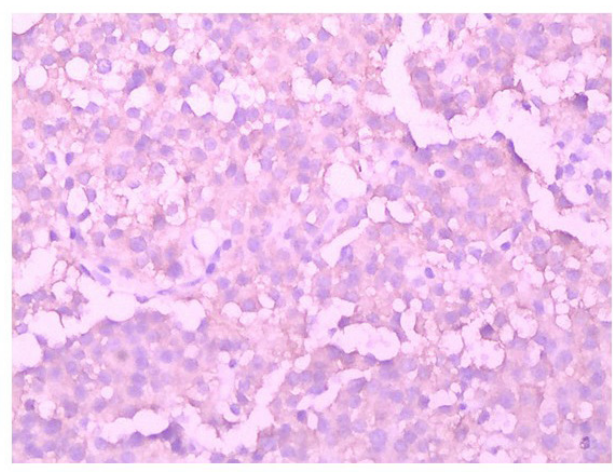

NIPA

Figure 2. TNF- $\alpha$ expression in invasive (IPA) and non-invasive (NIPA) pituitary adenoma specimens (hematoxylin and eosin stain, $10 \times 20$ magnification).

\section{Expression of IL-6 in IPA and NIPA specimens}

IL-6 staining was not observed in the negative control group. Of the 40 IPA specimens, $67.5 \%$ showed positive expression of IL- 6 , while such positive staining was seen in $22.5 \%$ of the 40 NIPA cases $(P<0.05$; Table 2 and Figure 3$)$.

Table 2. Expression of IL-6 in invasive (IPA) and non-invasive (NIPA) pituitary adenoma specimens.

\begin{tabular}{|c|c|c|c|c|c|c|c|}
\hline \multirow[t]{2}{*}{ Type of tumor } & \multirow[t]{2}{*}{$\mathrm{N}$} & \multicolumn{4}{|c|}{ IL-6 expression } & \multirow[t]{2}{*}{$\chi^{2}$ value } & \multirow[t]{2}{*}{$P$} \\
\hline & & - & + & ++ & +++ & & \\
\hline NIPA & 40 & 31 & 6 & 3 & 0 & 16.36 & $<0.05$ \\
\hline IPA & 40 & 13 & 7 & 15 & 5 & & \\
\hline
\end{tabular}

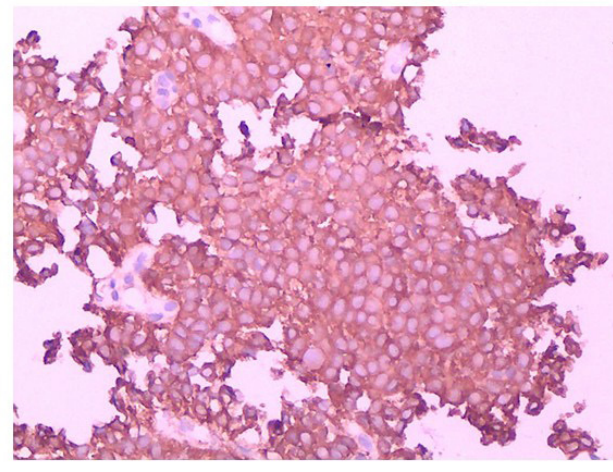

IPA

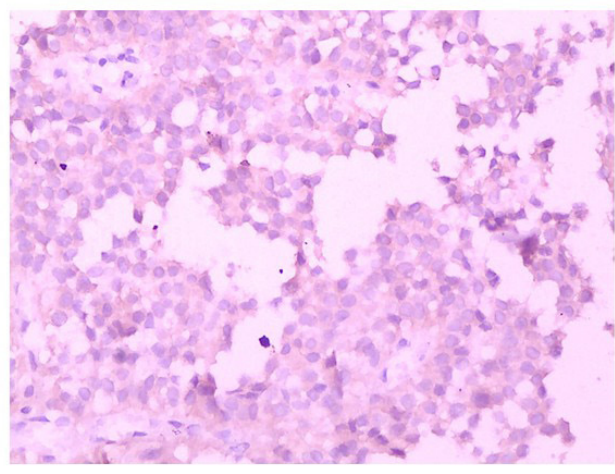

NIPA

Figure 3. IL-6 expression in invasive (IPA) and non-invasive (NIPA) pituitary adenoma specimens (hematoxylin and eosin stain, $10 \times 20$ magnification). 


\section{DISCUSSION}

\section{TNF- $\alpha$ and IPA}

Also known as cachectin, TNF- $\alpha$ is a small protein secreted by activated macrophages and monocytes. It plays crucial roles in the inflammatory response and cellular and tumor immunity (Cui et al., 2007). Komori et al. (1993) discovered in 1993 that TNF- $\alpha$ exerts effects similar to those of okadaic acid; for example, both facilitate the phosphorylation of vimentin and heat shock protein 27 in fibroblasts. However, TNF- $\alpha$ is substantially more potent than okadaic acid in this respect, showing an effect over 1000 times stronger. The proteins phosphorylated by both of these molecules can act as tumor promoters. Suganuma et al. (1999) discovered using experiments with mice that TNF- $\alpha$ plays an important role in tumor formation. IPA is histologically benign, although it shows malignant growth, penetrating the saddle area and invading surrounding structures. We found that TNF- $\alpha$ was clearly upregulated in IPA tissue compared to that of NIPA. It is generally believed that TNF- $\alpha$ promotes the invasive growth of pituitary adenomas by stimulating angiogenesis, a process involved in invasive expansion of tumor tissue. TNF- $\alpha$ increases the expression and mRNA stability of IL-8, thereby promoting the proliferation of endothelial cells, a key step in tumor angiogenesis (Berry et al., 2001). During active angiogenesis, IL-8 activates G proteins in vascular endothelial cells (VECs), which leads to the formation of stress fibers and causes cell contraction. The gaps between VECs increase, and the permeability of new blood vessels is enhanced, which further increases the invasiveness of tumor cells (Han et al., 2001). As the expression of matrix metalloproteinases is upregulated, more extracellular matrix is degraded and tumor angiogenesis is augmented, factors favoring invasive growth of pituitary adenomas.

\section{Increasing the invasiveness of pituitary adenoma cells}

TNF- $\alpha$ promotes the adhesion of tumor and endothelial cells, and on the transcriptional level, upregulates the expression of CD44v6 protein in cancerous cells. Moreover, TNF- $\alpha$ enhances the adhesion of cells to hyaluronic acid, a CD44v6 ligand. This facilitates the adhesion of tumor cells and extracellular matrix, exacerbating tumor cell invasiveness (Barshishat et al., 2002), thereby encouraging progression of IPA.

\section{Reducing the probability of IPA cells being attacked by immune cells}

TNF- $\alpha$ upregulates integrins-in particular, the $\alpha 3, \alpha 4$, and $\beta 1$ subunits. P- and E-selectin directly promote the adhesion of tumor cells and VECs, and P-selectin and P-integrin mediate platelet activation. Activated platelets bind to tumor cells, reducing the ability of immune cells to attack them. Thus, the activity of P-selectin and P-integrin represents an important mechanism underlying the invasive growth of tumor cells (Zhu et al., 2002; Chen and Geng, 2006). The significantly reduced expression of TNF- $\alpha$ in NIPA compared to IPA tissue suggests that the above mechanisms are responsible for the invasiveness of some pituitary adenomas.

\section{IL-6 and IPA}

Weissenbach first discovered IL-6 in 1980, naming it interferon $\beta 2$. As more research was carried out on this protein, many other names were assigned to it, including hybridoma- 
plasmocytoma growth factor, hepatocyte stimulating factor, and B cell growth factor. The name it carries today was not formally established until the cell factor of interest was cloned and an agreement was reached between researchers. Participating in immune responses, cell proliferation, and regulation of blood cell differentiation, IL-6 has one of the widest functional ranges of any currently identified cellular protein, and facilitates the production of various cells. IL- 6 was first characterized as an inflammatory factor and was later found to be involved in tumor occurrence, development, invasion, and metastasis (Liu et al., 2011).

Some scholars have associated IL-6 with the invasive growth of pituitary adenomas (Zou et al., 2008), and here, we focus on the mechanism by which this protein may promote such growth. Their malignant behavior makes IPAs similar to malignant tumors in terms of occurrence and developmental mechanism. IL-6 has both pro-inflammatory and anti-inflammatory effects. It has been found that the upregulation of IL- 6 and associated abnormal signaling is involved in the occurrence, development, and poor prognosis of various tumors (Hodge et al., 2005; Tchirkov et al., 2007). Our study showed that IL-6 was significantly upregulated in IPA specimens, consistent with the general belief that high expression of this protein facilitates tumor growth.

As mentioned above, tumor development is strongly dependent on angiogenesis. Proangiogenic growth factors contribute to tumor invasiveness, favoring tumor development. IL-6 also exhibits angiogenesis-promoting effects. Nilsson et al. (2005) reported that IL-6 was not always upregulated in ovarian cancer cells in vitro. However, all such cell lines showed an upregulation of IL-6 and IL-6 receptor when inoculated into nude mice. In the same study, it was also found that IL-6 demonstrates a chemotactic effect on VECs, and hence promotes angiogenesis. Liu et al. (2014) discovered that the regulation of IL-6 secretion in pituitary adenomas promotes tumor angiogenesis, contributing to tumor invasiveness. It is generally understood that this mechanism consists of the activation of JAK/STAT and Ras/Erk signaling pathways in tumor cells through the binding of IL-6 to its receptor. Consequently, a large amount of vascular endothelial growth factor is secreted by tumor cells, thus stimulating angiogenesis (Hong et al., 2007). Invasiveness is a major factor related to tumor malignancy. Kanazawa et al. (2007) showed that IL-6 directly affects tumor invasion, influencing tumor cell proliferation and increasing their invasiveness. Histologically, IPA specimens are characterized by active mitosis, while in terms of biological behavior, they show invasive growth. However, these properties are not evident in NIPA. We found by immunohistochemical staining that IL-6 was significantly upregulated in IPA specimens compared with those from NIPAs, indicating a role for this protein in IPA development. Indeed, reports already exist concerning the clinical use of IL-6 antagonist monoclonal antibodies in cancer treatment (Fulciniti et al., 2009).

In summary, we detected the expression of TNF- $\alpha$ and IL-6 using a streptavidin peroxidase immunohistochemical method. Our results suggest that the upregulation of these two proteins promotes the invasive growth of pituitary adenomas. This finding provides new evidence for studies into the occurrence, progression, and prognosis of IPA, as well its clinical treatment.

\section{Conflicts of interest}

The authors declare no conflict of interest.

\section{REFERENCES}

Barshishat M, Ariel A, Cahalon L, Chowers Y, et al. (2002). TNFalpha and IL-8 regulate the expression and function of CD44 variant proteins in human colon carcinoma cells. Clin. Exp. Metastasis 19: 327-337. http://dx.doi.org/10.1023/A:1015528314970 Berry KK, Varney ML, Dave BJ, Bucana CD, et al. (2001). Expression of interleukin-8 in human metastatic endometrial 
carcinoma cells and its regulation by inflammatory cytokines. Int. J. Gynecol. Cancer 11: 54-60. http://dx.doi.org/10.1046/ j.1525-1438.2001.011001054.x

Chen M and Geng JG (2006). P-selectin mediates adhesion of leukocytes, platelets, and cancer cells in inflammation, thrombosis, and cancer growth and metastasis. Arch. Immunol. Ther. Exp. (Warsz.) 54: 75-84. http://dx.doi.org/10.1007/ $\underline{\text { s00005-006-0010-6 }}$

Cui LF, Guo XJ and Fu L (2007). Advances in study of the relationship of TNF- $\alpha$ with development and progression of tumors. Chinese Journal of Breast Disease 1: 236-240.

Fulciniti M, Hideshima T, Vermot-Desroches C, Pozzi S, et al. (2009). A high-affinity fully human anti-IL-6 mAb, 1339, for the treatment of multiple myeloma. Clin. Cancer Res. 15: 7144-7152. http://dx.doi.org/10.1158/1078-0432.CCR-09-1483

Han YP, Tuan TL, Wu H, Hughes M, et al. (2001). TNF-alpha stimulates activation of pro-MMP2 in human skin through NF(kappa)B mediated induction of MT1-MMP. J. Cell Sci. 114: 131-139.

Hodge DR, Hurt EM and Farrar WL (2005). The role of IL-6 and STAT3 in inflammation and cancer. Eur. J. Cancer 41: 25022512. http://dx.doi.org/10.1016/j.ejca.2005.08.016

Hong DS, Angelo LS and Kurzrock R (2007). Interleukin-6 and its receptor in cancer: implications for translational therapeutics. Cancer 110: 1911-1928. http://dx.doi.org/10.1002/cncr.22999

Jefferson G (1940). Extrasellar Extensions of Pituitary Adenomas: (Section of Neurology). Proc. R. Soc. Med. 33: 433-458.

Kanazawa T, Nishino H, Hasegawa M, Ohta Y, et al. (2007). Interleukin-6 directly influences proliferation and invasion potential of head and neck cancer cells. Eur. Arch. Otorhinolaryngol. 264: 815-821. http://dx.doi.org/10.1007/s00405-007-0264-6

Komori A, Yatsunami J, Suganuma M, Okabe S, et al. (1993). Tumor necrosis factor acts as a tumor promoter in BALB/3T3 cell transformation. Cancer Res. 53: 1982-1985.

Liu H, Zhu B and Lin ZH (2011). IL-6 signaling pathway and tumors. Chinese Journal of Cellular and Molecular Immunology 27: 353-355.

Liu YY, Zhou JB, Wang K, Long QF, et al. (2014). Expression of IL-6 and its relationship to microvessel density and invasiveness of pituitary adenomas. Chinese Journal of Minimally Invasive Neurosurgery 19: 424-426.

Nilsson MB, Langley RR and Fidler IJ (2005). Interleukin-6, secreted by human ovarian carcinoma cells, is a potent proangiogenic cytokine. Cancer Res. 65: 10794-10800. http://dx.doi.org/10.1158/0008-5472.CAN-05-0623

Rey JA, Bello MJ, de Campos JM, Kusak ME, et al. (1986). A case of pituitary adenoma with 58 chromosomes. Cancer Genet. Cytogenet. 23: 171-174. http://dx.doi.org/10.1016/0165-4608(86)90415-2

Roelfsema F, Biermasz NR and Pereira AM (2012). Clinical factors involved in the recurrence of pituitary adenomas after surgical remission: a structured review and meta-analysis. Pituitary 15: 71-83. http://dx.doi.org/10.1007/s11102-011-0347-7

Suganuma M, Okabe S, Marino MW, Sakai A, et al. (1999). Essential role of tumor necrosis factor alpha (TNF-alpha) in tumor promotion as revealed by TNF-alpha-deficient mice. Cancer Res. 59: 4516-4518.

Tchirkov A, Khalil T, Chautard E, Mokhtari K, et al. (2007). Interleukin-6 gene amplification and shortened survival in glioblastoma patients. Br. J. Cancer 96: 474-476. http://dx.doi.org/10.1038/sj.bjc.6603586

Wang ZC (2005). Wang Zhongcheng Neurosurgery. Hubei Science \& Technology Press, Wuhan. Edition 1.

Zhu N, Eves PC, Katerinaki E, Szabo M, et al. (2002). Melanoma cell attachment, invasion, and integrin expression is upregulated by tumor necrosis factor alpha and suppressed by alpha melanocyte stimulating hormone. J. Invest. Dermatol. 119: 1165-1171. http://dx.doi.org/10.1046/j.1523-1747.2002.19516.x

Zou ZY, Zhu B, Hu J and Yuan CL (2008). Relationship between expression of VEGF and secretion oflL-1 and IL-6 in human pituitary adenoma cells. Medical Journal of National Defending Forces in Southwest China 18: 30-32. 